\title{
$O$ debate retomado: conflitos e convergências entre comunicação e informação ${ }^{1}$
}

\section{Maria Helena Weber}

Doutora;Universidade Federal do Rio Grande do Sul

maria.weber@ufrgs.br

\section{Ida Regina Stumpf}

Doutora; Universidade Federal do Rio Grande do Sul

ida.stumpf@ufrgs.br

\section{Resumo}

Este artigo se inscreve na memória do Programa de PósGraduação em Comunicação e Informação da Universidade Federal do Rio Grande do Sul, como parte de um debate permanente sobre dois campos de conhecimento: Comunicação e Ciência da Informação. Publicado originalmente, em 2003, o artigo amplia a problematização do paradoxo sobre a autonomia epistemológica dos dois campos e a sua dependência políticoinstitucional. Em vinte anos, a consolidação do PPGCOM/UFRGS respondeu à crítica das sucessivas avaliações que questionavam a sua área de concentração - Comunicação e Informação. A resistência e experiência do Programa, hoje, podem contribuir para o debate sobre a necessária interdisciplinaridade da ciência, de acordo com o Plano Nacional de Pós-Graduação 2010-2020. A reescritura desse artigo se situa nessa direção, tendo por base as perspectivas históricas e conceituais que permitem a identificação de três dimensões de interdisciplinaridade entre Comunicação e Informação: dependência, mediação e intervenção.

\section{Palavras-chave}

Comunicação. Ciência da Informação. Interdisciplinaridade. PPGCOM. UFRGS.

Um dos fenômenos mais inquietantes do espírito humano é o esquivar-se do concreto. Possuímos uma acentuada tendência a nos lançarmos sempre ao longínquo, indo constantemente de encontro a tudo aquilo que, estando imediatamente à nossa frente, deixamos de ver.

Elias Canetti - A consciência das Palavras

\footnotetext{
${ }^{1}$ Título do texto original: Comunicação e Informação: conflitos e convergências, publicado como capítulo no livro Epistemologia da Comunicação, organizado por Maria Immacolata Vassalo de Lopes (STUMPF; WEBER, 2003).
} 


\section{Introdução}

Em tempos de debates sobre interdisciplinaridades, produção de conhecimento e avaliação, esse texto pretende retomar o debate sobre a proximidade dos campos Comunicação e Ciência da Informação justificada pelo percurso de 20 anos de permanência estratégica na constituição do Programa de Pós-Graduação em Comunicação e Informação (PPGCOM), na Universidade Federal do Rio Grande do Sul (UFRGS). A construção dos projetos de mestrado e doutorado foi realizada, principalmente, a partir de decisões e práticas políticas e institucionais - mais do que conceituais, que consolidaram esses cursos, apesar das críticas e avaliações que o colocavam em posição de fragilidade. Atualmente, este é o programa que tem experiência e pode responder às diretrizes sobre a desejada interdisciplinaridade nas ciências, como explicita o Plano Nacional de Pós-Graduação 2011-2020 (PNPG) divulgado pela Coordenação de Aperfeiçoamento de Pessoal de Nível Superior (CAPES) especificamente, na área Ciências Sociais Aplicadas (BRASIL, 2010). Esta situação é propícia para retomar o debate iniciado no texto de 2003, sob o título Comunicação e Informação: conflitos e convergências.

Mesmo escrito e ordenado de outra forma, pretendemos alinhar as perspectivas teóricas, históricas, políticas e institucionais que tensionam e desafiam a história do PPGCOM/UFRGS, tendo em vista o paradoxo identificado entre a proximidade históricoinstitucional e distanciamento teórico-conceitual. A superação de divergências esteve na dedicação dos pesquisadores docentes para a qualificação do programa ao investir no melhor formato de linhas e projetos de pesquisa e na produção intelectual que pudessem contemplar os dois campos e justificar a unidade. Mesmo assim, esse processo sempre esteve sob o questionamento das agências de avaliação. A proposta do doutorado, em 2000, por exemplo, foi realizada sob muita tensão, pois a manutenção das duas áreas colocava em risco sua aprovação, mas o projeto defendia a continuidade dessa história, teórica e estruturalmente, argumentando em nome da autonomia da instituição e da liberdade de pensamento. A manutenção dessa unidade era a única alternativa para crescer e o programa ganhou a aposta: aprovou o doutorado e conquistou a nota cinco.

Durante esses longos anos foram feitos arranjos de convivência institucional e intelectual, em linhas de pesquisa, em disciplinas e na administração do Programa, mas a desejada interdisciplinaridade conceitual ainda se impõe como desafio. Se examinarmos os projetos de pesquisa em desenvolvimento, a temática das teses e dissertações, a formação das bancas examinadoras e, especialmente, a produção intelectual do Programa, dificilmente a interdis- 
ciplinaridade será identificada. Por isso, a retomada deste artigo e a questão: por que duas áreas tão próximas quanto aos seus objetos de estudo não conseguem criar objetos de pesquisa comuns às duas perspectivas? Uma das respostas reside, evidentemente, na abordagem epistemológica, pouco desenvolvida.

Compartilhar tensões e debates sobre limites, convergências das áreas, conflitos temáticos, institucionais e políticos vivenciados pelos docentes e alunos do programa permitiu solidificar o projeto PPGCOM/UFRGS, mas essa resistência não foi suficiente para torná-lo interdisciplinar. Um dos indicadores reside na origem da criação do Programa justificado pelo investimento de docentes oriundos de dois departamentos distintos (Comunicação Social e Biblioteconomia e Documentação) que formaram, nos anos 70, a Faculdade de Biblioteconomia e Comunicação² - Fabico, por decisão político-institucional em obediência ao governo militar e às novas diretrizes para a universidade brasileira.

O debate ainda se impõe, também, na medida em que Comunicação e Informação são as marcas da contemporaneidade, em uma sociedade dependente de informações e de processos comunicacionais ininterruptos, submetida à tecnologia e à supremacia da imagem. Acompanha o próprio desenvolvimento do PPGCOM a pretensão de ampliar e aprofundar este debate, trazendo à tona questões paradoxais e epistemológicas suscitadas pelas dimensões tecnológicas e sociais das mediações entre informação e comunicação; sobre as relações geradas pelo acesso, transmissão e recepção/utilização de informações; sobre a comunicação entendida como processo na transmissão de informações; sobre as práticas e profissões mantidas pelas duas áreas; sobre o caráter simbólico da comunicação; sobre as diferentes e, ao mesmo tempo, complementares formas de intervenção social, cultural e política das duas áreas; sobre as rupturas e aproximações dos paradigmas que atribuem à Ciência da Informação a proeminência da técnica e à Comunicação o caráter social das suas ações.

0 debate exerce uma tensão criativa e impulsionadora e essa reescritura tem por objetivo expandir questões de ordem epistemológica que permitam relacionar a matéria-prima da Informação e da Comunicação ao sentido gerado, através dos diferentes modos de registrar (informação) e interpretar (comunicação) a realidade e suas representações. Contribuem para isto a consolidação do PPGCOM/UFRGS e a sua resistência a contínuas e desqualificadoras avaliações devido à manutenção e defesa das duas áreas fundadoras. Neste sentido, podem contribuir para ratificar a interdisciplinaridade como referencial a ser atingido pelo

\footnotetext{
${ }^{2}$ Atualmente a Fabico abriga quatro Cursos (Arquivologia, Museologia, Biblioteconomia e Comunicação Social com três habilitações: Jornalismo, Propaganda/Publicidade e Relações Públicas), com algumas disciplinas comuns.
} 
sistema de pós-graduação do país. As questões fundadoras persistem no paradoxo que mostra, simultaneamente, proximidades e dependências institucionais e o distanciamento conceitual e temático da produção intelectual.

A problematização de questões relacionadas a conflitos e convergências entre os campos da Comunicação e da Informação remete à interface comunicação/informação para que sejam compreendidos na sua interdisciplinaridade, o que pressupõe a autonomia de cada campo. Para tanto, ratificamos as três dimensões de análise que permitem identificar a convergência: dependência, mediação e intervenção. Essas dimensões podem ser identificadas tanto na perspectiva epistemológica quanto institucional e histórica. Para tanto, é necessário abordar as questões conceituais que identificam e deram autonomia às duas áreas e aquelas histórico-institucionais que as tornaram dependentes.

\section{Perspectivas conceituais}

Ao distanciamento teórico possível entre Informação e Comunicação, correspondem lógicas de aproximação, de ordem histórica, política e técnica, engendradas pelas duas áreas de conhecimento. Este esforço reside na evidência de que Informação e Comunicação interferem diretamente no modo de entender, registrar e intervir no mundo, num processo contínuo e indispensável para qualquer área do conhecimento e atividade humana. Como tal, determinam o acesso às coisas do mundo, assim como indicam como a ele pertencer, num processo permanente para tornar visíveis os acontecimentos, coisas e sujeitos. Neste sentido, Comunicação e Informação poderiam ser entendidas como partes indissociáveis, devido a sua interdependência, pois a informação só existe quando é comunicada e a comunicação não existe sem a informação.

A perspectiva epistemológica que mantém as questões em torno dos conflitos e convergências dos campos da Comunicação e Ciência da Informação incide sobre a identificação do objeto. Enquanto os saberes, disciplinas e práticas relacionados à Informação são entendidos e denominados como ciência (Ciência da Informação), o campo da Comunicação questiona seus saberes, práticas e disciplinas em busca da definição de seu objeto. Todas as áreas de conhecimento, cada vez mais, dependem dos saberes executados pela Ciência da Informação. A cada dia, a complexidade da comunicação é determinada por tecnologias, mídias e profissões, que ampliam o questionamento sobre o poder disso na transformação de realidades e do modo de viver. Este questionamento mantém a Comunicação como um campo de 
conhecimento sobre o qual se debruçam outras ciências, por ele afetadas, mas que ainda não usufruiu do estatuto de ciência.

Nos conceitos sobre comunicação está implícita a ideia de inter-relação, assim como o conteúdo da informação "[...] é o rastro que uma consciência deixa sobre um suporte material de modo que uma outra consciência pode resgatar, recuperar, então simular, o estado em que se encontrava a primeira consciência.", afirma Martino (2001, p.17) e complementa que "[...] a informação é uma comunicação que pode ser ativada a qualquer momento." (MARTINO, 2001, p. 17). A autonomia teórica da Comunicação e também da Informação pode ser identificada na formação de seus profissionais e na produção científica específica. Há uma interdependência, no entanto, em práticas expressas nos sistemas de armazenamento e acesso da área da Informação. Essas aproximações e distanciamentos teóricohistóricos mantêm esse debate, tanto no plano das aproximações físicas e técnicas quanto no plano teórico.

Historicamente, as áreas de Comunicação e de Informação, no Brasil, tiveram seus caminhos cruzados, num certo momento, seguidos de uma ruptura que foi restaurada, num certo aspecto, e em nível de pós-graduação. Para seguir suas trajetórias, faz-se necessária, primeiramente, uma reconstituição histórica dos fatos. No contexto internacional, a Informação, como uma área de estudos, surgiu no período pós-guerra, como fruto do desenvolvimento do computador para tratamento e recuperação dos registros do conhecimento. Por situar neste contexto a origem da área Informação, os autores a vinculam à Biblioteconomia, embora tendo conceitos, teorias e objetos próprios. 0 conceito de informação passou a ser trabalhado, mas pela importância que a Ciência e a Tecnologia passaram a ter para a sociedade e como força propulsora para o desenvolvimento dos países, naquele momento, referia-se especificamente à informação científica e tecnológica, sendo os Estados Unidos e Inglaterra o berço destes estudos. A Teoria Matemática da Comunicação, criada por Shannon e Weaver em 1949 (WOLF, 2001), foi baseada em conceitos matemáticos que explicavam a interação como processamento, transmissão e recepção de informação, sendo seu conteúdo ao mesmo tempo ordenador e ordenado. Este paradigma passou a vigorar como explicativo dos problemas relacionados à Comunicação e à Informação, independentemente do tipo de mensagem veiculada, seja de natureza científica, tecnológica, social, artística, afetiva, ou de outra ordem.

O campo da Comunicação foi sendo constituído pelos estudos sobre os efeitos da propaganda e ações políticas na formação da opinião; sobre a organização e o poder da impren- 
sa; sobre o impacto da massificação da informação sobre o comportamento da sociedade, dos indivíduos e a formação da opinião pública. A industrialização, a globalização, a sociedade de massas, a glamourização do consumo foram alterando os estudos e, especialmente, a partir dos anos 1960, o campo da Comunicação passa a ser considerado por outras ciências. As tentativas de compreender o funcionamento da sociedade e a mudança de comportamento passam pela compreensão dos conteúdos e pelo funcionamento dos grandes media. A partir dos anos 70, muitas abordagens sedimentam as ideias sobre o poder dos meios de comunicação.

Novas perspectivas teóricas sobre processos, estratégias, tecnologias da comunicação indicam o poder dos media na apreensão e interpretação da realidade, tanto importunam quanto contribuem para diferentes áreas de conhecimento, conforme pode ser identificado no alinhamento teórico, proposto por Wolf, em nove modelos teóricos relacionados a "momentos":

[...] a teoria hipodérmica, a teoria ligada à abordagem empíricoexperimental, a teoria que deriva da pesquisa empírica de campo, a teoria de base estrutural-funcionalista, a teoria crítica dos mass media, a teoria culturológica, os cultural studies e as teorias comunicativas. (WOLF, 2001, p. 22)

A profissionalização da comunicação e as novas teorizações sustentam-se sobre três perspectivas principais. A primeira é compreensiva e entende o poder da comunicação, da tecnologia vinculada como a diluição do meio na mensagem e como extensão do movimento humano, como entendia McLuhan (1974). Com a mesma intensidade, a indústria cultural torna-se o conceito do pensamento crítico que aponta para a relatividade da qualidade dos media perversos destinados à manipulação das informações e ao controle das mentes, como nos diz o legado de Adorno, Horkheimer, Benjamin, entre outros. Em terceiro lugar, podem ser identificados os estudos sobre as funções e atividades profissionais do campo da comunicação, especificamente, o jornalismo, a propaganda, relações públicas que se somaram a pesquisas sobre a televisão, o rádio, cinema, imprensa e outros meios. No Brasil, a formação de pesquisadores e profissionais, em escolas de comunicação, publicidade/propaganda e relações públicas é realizada entre as práticas e as tensões conceituais sobre estas. A problematização sobre o poder da comunicação dos media, suas práticas, conteúdos e abrangência tem mantido o debate epistemológico sobre qual é o seu objeto. A importância desse campo para a visibilidade das dinâmicas sociais e políticas não parece ser suficiente, no entanto, para a sua delimitação como ciência, ao contrário da Ciência da Informação. 
Quanto ao caminho da Informação, ao final da década de 60 passou a ser chamada de Ciência da Informação, influenciando a denominação de institutos. 0 American Documentation Institute passou a chamar-se American Society for Information Science e no Reino Unido surgiu o Institute for Information Scientist. A Ciência da Informação era definida como

[...] aquela disciplina que investiga as propriedades e o comportamento da informação, as forças que governam seu fluxo e os meios de processamento para o acesso e uso otimizados. Ela diz respeito àquele corpo de conhecimentos ligados à origem, coleta, organização, armazenagem, recuperação, interpretação, transformação e utilização da informação (BORKO, 1968, p.3).

A Ciência da Informação é revestida de um componente de ciência que investiga as propriedades gerais da informação (natureza, gênese, efeitos), a análise de seus processos (de construção, comunicação e uso), bem como a concepção e o desenvolvimento de aplicações, através da criação de produtos e serviços (LE COADIC, 1996). A Ciência da Informação surge, então, com o estatuto de Ciência, ao menos na sua denominação. Atualmente, na Inglaterra, esta pretensão foi amenizada nos departamentos universitários para Information Studies, ou, quando ligada à Biblioteconomia, denominada de Library and Information Studies.

A Ciência da Informação e a Comunicação constituíram sua identidade a partir das Ciências Sociais, sendo ambas entendidas como Ciências Sociais Aplicadas, uma vez que seu objetivo mais amplo está relacionado aos problemas de informação e comunicação da sociedade. $O$ alcance deste objetivo levou a área a buscar nas teorias sociais as explicações sobre a Informação como fenômeno que acontece no seio da sociedade. A Sociologia da Ciência, por exemplo, passou a ser utilizada para explicar como se dá a produção e circulação do conhecimento científico nas comunidades de pesquisadores. Em relação à Comunicação, a problematização esteve relacionada a categorias sociológicas, artísticas, da imagem e da linguagem que serviam para interpretar os fenômenos comunicacionais gerados pelas dinâmicas da sociedade e dos meios.

Em relação à autonomia da Ciência da Informação, os teóricos sempre a colocaram como multidisciplinar, mantendo as características de ciência moderna que mantém interfaces com outros campos do conhecimento, especialmente com a Biblioteconomia, a Ciência da Computação, a Linguística, as Ciências Cognitivas e a Comunicação, entre outras.

Algumas dessas ligações sempre foram muito claras, como com a Biblioteconomia, porque grande parte dos registros da informação, ao menos até o momento, encontra-se no formato livro e demais documentos gráficos, iconográficos, auditivos, etc. que sempre foram 
objeto de estudo e de tratamento por essa área. A Ciência da Computação, igualmente, mantém uma ligação grande com a Ciência da Informação porque só através dela foi possível tratar, armazenar e disponibilizar a quantidade de informação produzida atualmente. Sem falar na criação de bancos de dados e de redes, que permitiram circular de forma mais estruturada a informação coletada, selecionada e tratada por processos informatizados. A Linguística é outra área que mantém estreita ligação com a Ciência da Informação, pois a representação da Informação passa por um processo verbal que precisa ter seus termos controlados a fim de permitir armazenagem e recuperação adequadas e evitar perdas.

Em relação às ciências cognitivas, cada vez mais é percebida sua ligação com a Ciência da Informação, uma vez que a preocupação desta é disponibilizar informações significativas com a competência de gerar conhecimento no indivíduo (BARRETO, 2002), e a daquela é entender como se dá a apropriação do conhecimento pelo indivíduo. Com a área de Comunicação a ligação parece ficar muito clara para quem trabalha com Informação, mas reducionista para quem trabalha com a Comunicação, já que para a Ciência da Informação, a Comunicação é vista como parte do processo de transferência de informação. Tanto assim que na construção do fluxo informacional, Le Coadic (1996) apresenta um modelo baseado em três grandes etapas - construção, comunicação e uso. Nele, a comunicação é um processo intermediário que permite a troca de informações, através de relações de alguma ordem, no qual a informação é um produto, uma substância, uma matéria. Esses conceitos restritivos são às vezes reforçados ou condenados por estudiosos das duas áreas, mas podem ser diferenciadas as propostas. Enquanto a Informação se apresenta com a possibilidade de alterar a estrutura cognitiva do sujeito, a Comunicação opera com os efeitos de sentido que irá operar no receptor "[...] sem que necessariamente ofusque a informação propriamente dita e que dela possa dispensar." (TAVARES, 2002, p. 140).

A concepção de informação como produto, com potencialidade para ser consumida, foi reforçada pela sua vinculação com a tecnologia, uma vez que o volume de informações circulantes, na atualidade, só pode ser armazenado por processos tecnológicos automatizados. No entanto, a associação da informação com a matéria e a tecnologia é puramente de ordem prática, pois seu potencial é "[...] gerar conhecimento para o indivíduo e para seu meio de convivência." (BARRETO, 2002) e associada, portanto, à cognição do indivíduo e ao seu meio social.

A demarcação das fronteiras entre Comunicação e Informação é realizada, também, na formação dos profissionais e na visão construída de uma sobre a outra, além da relação es- 
tabelecida entre ambas. Bernard Miège (1995, p.92) refere-se à interdependência entre os dois campos afirmando que "[...] a comunicação não se opõe a informação, mas a prolonga; as duas noções são frequentemente indissociáveis; e as críticas feitas a uma [...] valem de igual modo para a outra." Continuando, ele afirma ainda que "[...] a informação não é produzida apenas para ser distribuída, pois é concebida em função de uma certa representação (sociocultural) dos leitores e telespectadores". No entanto, equivocam-se teoricamente os especialistas em informação quando pensam que seu trabalho pode existir sem uma dimensão cultural e simbólica, que, em última instância, remete à própria estrutura e natureza da sociedade (UFRGS; PPGCOM, 2000).

Vistas sob esse prisma, Informação e Comunicação são inseparáveis. Mesmo sendo vistas num sentido estrito, ora como produto, ora como processo, confirma-se o caráter intercambiável entre ambas, quando se identifica um caráter transformador também na Informação, dentro da noção de conhecimento a ela associado. Este conhecimento permitirá, sob quaisquer circunstâncias, mudanças nas conformações sociais, onde podem ser identificadas as práticas comunicacionais. Pode-se assim questionar a rigidez epistemológica das demarcações de fronteiras entre as duas áreas, considerando as práticas e dependências reais. Para estas questões ainda não existem respostas convincentes, por isto o debate é mantido, frente à "[...] redescoberta e revalorização da dimensão simbólica e interpretativa das trocas sociais que, paradoxalmente, estavam sendo realimentadas pelas novas tecnologias da informação." (UFRGS, 2000).

A complementaridade é identificada mais facilmente do que a interdisciplinaridade, como indicam as classificações das instituições de avaliação e fomento da pesquisa e da pósgraduação, como a CAPES e o Conselho Nacional de Desenvolvimento Científico e Tecnológico (CNPq). 0 paradoxo da interdisciplinaridade se mescla com questões institucionais, legais e políticas do contexto histórico brasileiro.

\section{Perspectivas Históricas}

No final dos anos 60, o fortalecimento do regime militar no Brasil gera uma nova Lei de Diretrizes e Bases da Educação Nacional (BRASIL, 1968) que adaptou as universidades e currículos a determinada concepção de educação superior e formação de mão de obra para um mercado em expansão. Nesse processo, os cursos de Comunicação foram institucionalizados, com a absorção dos cursos de Jornalismo - os quais em sua maioria estavam vinculados aos Institutos de Filosofia e Ciências Humanas -, e pela criação das novas habilitações, 
Relações Públicas, Publicidade e Propaganda. Mais tarde, seriam formatados os cursos de Radialismo, Televisão, Cinema e Editoração. Práticas profissionais e currículos foram abrigados sob o grande guarda-chuva da Comunicação.

Como parte dessa reestruturação, os cursos de Biblioteconomia, até então ligados a outras unidades universitárias, permaneceram com esta denominação, mas foram tornados independentes na categoria de escolas, institutos ou departamentos, como na Universidade Federal de Minas Gerais (UFMG), ou foram unidos aos cursos de Comunicação na forma de faculdades, como na Universidade Federal da Bahia (UFBA) e na UFRGS. É neste momento que a Biblioteconomia poderia ter incorporado a denominação Ciência da Informação ou apenas Informação, ou mesmo a substituído para abrigar um grupo de cursos das práticas profissionais que incluem Biblioteconomia, Arquivologia e Museologia, hoje implantados em algumas Universidades. Na institucionalização da Ciência da Informação, em âmbito mundial, Le Coadic (1996) informa que, em muitos lugares, os cursos se associaram com os cursos de Biblioteconomia ou lhes deram continuidade. A Arquivologia e a Museologia, no entanto, até hoje discutem a sua vinculação à grande área da Ciência da Informação e se o seu objeto de estudo é a informação, o documento arquivístico ou museológico (FONSECA, 2002). Não podemos ser muito críticos em relação a estas denominações e incorporações, pois à época da reestruturação do ensino superior brasileiro, a Ciência da Informação encontrava-se em estágio prematuro, especialmente no Brasil. Nas universidades que decidiram pela junção dos cursos de Comunicação e Biblioteconomia, isto pode ser considerado como estratégia política, servindo aos governos militares para neutralizar a voz dos "politizados e atuantes" comunicadores pela convivência com os "passivos" bibliotecários. Institucionalmente, não foram questionados os fundamentos da união destas duas áreas de conhecimento que hoje existe em poucas universidades, como na Universidade de São Paulo (USP) e na UFRGS.

Nos anos 70, este panorama passa por uma nova configuração, com a criação dos primeiros cursos de pós-graduação, quando as duas áreas implantam programas próprios, à exceção da USP. Alguns cursos de mestrado e depois de doutorado em Comunicação tiveram sua origem nos cursos de Letras ou eram, inicialmente, programas de pós-graduação em Literatura (CAPPARELLI; STUMPF, 1998), uma área considerada mais "nobre", não tendo causado muita celeuma. Talvez porque os docentes provenientes de tais cursos pesquisavam Semiótica, aceita como campo conceitual e metodológico, também, para os estudos da Comunicação. Foi nesta época que a Ciência da Informação se instalou no Brasil, através da criação do mestrado em Ciência da Informação do Instituto Brasileiro de Bibliografia e Do- 
cumentação - IBBD -, hoje Instituto Brasileiro de Informação em Ciência e Tecnologia - IBICT. Os demais cursos de pós-graduação criados nesta época, na Universidade de Brasília UnB e na Universidade Federal de Minas Gerais - UFMG -, mantiveram a denominação de Biblioteconomia, modificando sua denominação para Ciência da Informação nos anos 90, quando passaram a incluir os conceitos e as teorias que regem a área. Também nessa última década alguns departamentos universitários incorporaram a palavra Informação à Biblioteconomia ou alteraram sua denominação para Ciência da Informação.

Oposta a essa tendência foi a experiência da UFRGS, que transformou o Programa de Pós-Graduação em Comunicação para Comunicação e Informação, quando a linha de pesquisa Informação e Novas Tecnologias - hoje denominada Informação, Tecnologia e Sociedade - fortaleceu sua constituição. Essa formação representou um redimensionamento dos dois campos, mantido como um desafio contínuo, com implicações teóricas, técnicas e institucionais, tanto em relação ao processo ensino-aprendizagem quanto no desenvolvimento de pesquisas e ações interdisciplinares. Na mesma unidade de ensino - Fabico, enquanto os cursos de graduação são ampliados e podem funcionar de forma autônoma quanto aos currículos, práticas e conteúdos, os cursos de pós-graduação dependem da integração destes. 0 funcionamento do PPGCOM tem sido justificado por alianças entre as duas áreas e beneficiado por arranjos, majoritariamente, institucionais e administrativos. A construção da interdisciplinaridade e a decorrente produção de conhecimento ainda não obtiveram êxito, mesmo que possam ser identificadas algumas combinações teórico-pedagógicas e projetos.

O rápido panorama traçado de uniões forçadas, rupturas e religações resgata apenas uma sequência de fatos que ocorreram, especialmente numa época em que a pesquisa era quase nula nas duas áreas e a ciência, em geral, era produzida isoladamente, já que a individualização do conhecimento era desejável. Hoje, porém, é essencial manter o debate sobre as interfaces entre Comunicação e Informação e seus elementos comuns para que, no futuro, sejam estabelecidas alianças mais harmônicas, em prol de um conhecimento mais integrado, enriquecendo a colaboração teórica e metodológica. Essa ideia é reforçada por Tavares (2002), quando afirma que tanto para uma quanto a outra "[...] cabem visões tecnológicas, educacionais e/ou sociológicas que podem ser complementares.". Segundo a autora:

[...] as fundamentações teóricas de ambas, informação e comunicação, quando estudadas em conjunto, precisam tornar-se mais consistentes e melhor definidas, no sentido de as colocarem sob o estatuto da ciência para que se chegue a resultados mais objetivos e precisos das pesquisas realizadas, inclusive para que as discussões quanto às acepções existentes diminuam para dar lugar a análises mais críticas de ambos os campos. Em 
nível epistemológico, o excesso de conceitos escolhidos sem uma reflexão crítica relacional tem contribuído para a apresentação de trabalhos equivocados. (TAVARES, 2002, p. 146-147).

Debater a interdisciplinaridade entre Comunicação e Informação beneficia as duas áreas, especialmente, quando as entendemos como definidoras da contemporaneidade, marcada pela ampliação dos poderes das redes de comunicação e sistemas midiáticos associados à "revolução da tecnologia da informação", como denomina Castells (2000). É nessa direção que vão sendo modificados comportamentos, referências culturais e criados novos procedimentos científicos e tecnológicos dirigidos a uma nova sociabilidade e novos processos de informação.

\section{Dimensões da interdisciplinaridade entre Comunicação e Informação}

Na mesma premissa que aponta os conflitos e as convergências que marcam as relações de poder entre os dois campos, identifica-se a sua indissociabilidade. Esse paradoxo permite identificar as três dimensões desse poder definido pela dependência, mediação e intervenção dos dois campos. A história das aproximações - conceituais e burocráticas entre Comunicação e Informação oferece subsídios para a formulação dessas três perspectivas, de cunho epistemológico, que fortalecem o instigante paradoxo constituído na vinculação e descolamento entre as duas áreas. Os mesmos argumentos podem ser utilizados tanto para expor as diferenças quanto as semelhanças, pois baseiam-se na aparência dos objetos de pesquisa cercados pela comunicação e aqueles da informação. Cáceres (2002) afirma que:

[...] as formas tecnológicas da informação e da comunicação buscam resolver problemas e perguntas emergentes de situações onde opera o vetor construtivo de uma e outra. A mente tecnológica quer resolver problemas e responder perguntas. No caso da informação se refere à ordem da representação e no caso da comunicação, à ordem da interação ${ }^{3}$. (CÁCERES, 2002, p. 9, tradução nossa).

A problematização da questão pode ser exemplificada com o produto "jornal", quando este atravessa o campo da comunicação e passa para o da informação (e vice-versa), transformado em parte de um objeto de pesquisa e não apenas como suporte. Concordâncias e divergências entre os campos da informação e da comunicação indicam claramente que a

\footnotetext{
${ }^{3}$ [...] las formas tecnológicas de la información y la comunicación lo que buscan es resolver problemas y preguntas emergentes de las situaciones donde el vector constructivo de una y otra opera. La mente tecnológica requiere resolver problemas y contestar preguntas. En el caso de la información se refieren al orden de la representación, en el caso de la comunicación al orden de la interacción. (CÁCERES, 2002, p .9).
} 
cada um competem poderes específicos, mas interdependentes. Pode-se afirmar que o poder do campo da Comunicação está na representação simbólica e mediações da realidade exercida pelos media e por todos os formatos de comunicação, da oral à digital. Como exemplos, a comunicação jornalística, cujas práticas implicam no desenvolvimento de tecnologias e pedagogias que viabilizam a apreensão, interpretação, produção e difusão de notícias e acontecimentos constituídos na ordem social, política, econômica e individual. A comunicação persuasiva também é demarcadora do campo da comunicação e, através de uma estética peculiar e da tecnologia, é estrategicamente planejada para convencer indivíduos e instituições (des)qualificando determinados fenômenos, instituições, sujeitos e objetos sociais, políticos e mercadológicos. Desse exercício contínuo, dependem a sociedade, as organizações e os indivíduos que transitam nas esferas públicas e privadas.

Em perspectiva complementar, menos complexa, mas não menos essencial, a Informação detém o poder de manter e expor o resultado desses processos vitais, informativos e persuasivos, tornando acessíveis seus resultados e gerando pesquisa. Da Ciência da Informação dependemos para que memórias e verdades sejam expostas e (re)constituídas. 0 poder da Informação está na dependência que todas as áreas de conhecimento e pessoas têm dos seus processos, tecnologias e espaços que permitem acessar dados, livros e produtos da produção de conhecimento, para que haja continuidade de pesquisa, para que realidades sejam reconhecidas e compartilhadas.

A grande diferença entre os dois campos de conhecimento parece residir no caráter persuasivo da comunicação. Ou seja, no processo comunicativo, identificável num diálogo ou na defesa de um projeto político, existe o encadeamento de argumentos retóricos, estéticas e formatos visando a defesa, a persuasão estrategicamente orientadas por um objetivo e resultados tangíveis. Trata-se, em essência, da possibilidade de manipular informações, processo inexistente nas práticas da Ciência da Informação.

Diante destas premissas, a interdisciplinaridade se impõe como problema epistemológico e sugere três dimensões dos conflitos, convergências e diferenças entre Comunicação e Informação, nomeadas como dependência, mediação e intervenção. Entendemos que estas dimensões indicam as pistas para ultrapassar a perspectiva institucional que tem marcado os dois campos, conforme explicitamos a seguir.

A dependência é a primeira das dimensões e refere-se à dependência científica da comunicação em relação à informação, na medida em que a rapidez, a quantidade e os diferentes formatos de material midiático, essencial à produção de conhecimento na comunicação, 
necessitam de armazenamento, recuperação e acessibilidade. As bibliotecas, hemerotecas, videotecas, arquivos e outros espaços são lugares que abrigam os produtos e conteúdos midiáticos constituídos por dados físicos e teóricos. Na contemporaneidade há uma tal quantidade de mídias e informações, que estas só poderão ser identificadas e pesquisadas se armazenadas, reunidas em lugar apropriado, cujo acesso e utilização só poderão existir através de códigos facilitadores. A atual convergência tecnológica transformou este lugar de informação - bibliotecas, museus, repositórios - numa das instâncias determinantes à própria existência das pesquisas acadêmicas e profissionais e da produção de conhecimento.

Mediação é a segunda dimensão, na qual podem ser identificadas as funções que caracterizam as atividades técnico-profissionais dos campos Comunicação e Informação. Na Informação há um processo permanente de mediação entre a informação gerada pelos registros sobre a realidade e os sujeitos que a eles terão acesso. Nestes procedimentos são construídas memórias culturais, políticas, científicas, econômicas, políticas e poéticas. São registrados os movimentos da sociedade, suas conquistas e seus produtos e disponibilizados para leitura ou pesquisa. Este armazenamento é essencial à existência da produção científica de qualquer campo de conhecimento, evidentemente, mas é das particularidades da associação entre as Ciências da Informação com a Comunicação que estamos ressaltando. Significa identificar a dependência da Comunicação em relação à Informação.

$\mathrm{Na}$ área da Comunicação, o processo de mediação é a sua própria essência, identificável nos movimentos contínuos de apreensão e representação da realidade disponibilizada através de mídias, linguagens e técnicas jornalísticas, publicitárias e promocionais. Através de ações, relações, profissionais e especialistas, a comunicação vai estabelecendo as mediações entre a realidade e os sujeitos; entre o mundo e a realidade; entre as mídias e os sujeitos. Com tal poder, a Comunicação conforma a realidade e comportamentos, explicitamente, quando sustentada por estratégias de persuasão e sofisticadas técnicas e a estética da propaganda e do marketing. Implicitamente, através da comunicação jornalística e das suas complexas redes de apreensão e codificação de notícias, onde se debatem interesses de todas as ordens, especialmente, mercadológicos e jornalísticos.

A terceira dimensão é denominada de intervenção, que identifica processos de intervenção social da Informação e da Comunicação. Ambos os campos são determinantes na constituição de saberes de todas as outras áreas de conhecimento. Entende-se que a disponibilização de informações e o respectivo acesso ao espaço são indicadores de formação cultural e educacional. Trata-se aqui de uma das feições mais importantes da cidadania. Os 
elos de pertencimento geográfico, cultural e histórico de um sujeito ocorrem, também, a partir do acesso às informações sobre a sociedade e a cultura à qual ele pertence. Esta ideia de pertencimento já é o resultado de um acúmulo de informações significativas. A tecnologia da informação e o espaço no qual as informações são armazenadas e facilitadas concorrem para a formação qualificada de um cidadão.

De outro lado, a intervenção da mídia tem a capacidade de alterar comportamentos pessoais, sociais e políticos, através da difusão de informações jornalísticas, publicitárias e de entretenimento. Essa difusão estará condicionada à natureza da comunicação e das profissões de comunicação mas, também, às relações estratégicas, à difusão de ideias e à comercialização da própria mídia, de produtos e eventos diversos. Além do exercício jornalístico, na intervenção da mídia podem ser identificados argumentos e processos persuasivos.

Compreendidas como dimensões hipotéticas sobre o poder dos campos da Comunicação e da Ciência da Informação, "dependência, mediação e intervenção" podem ser facilmente identificáveis nas fronteiras conceituais e técnicas entre estes campos. Pode-se inferir que a grande diferença reside na dimensão persuasiva inerente ao fazer comunicativo e inexistente na área da Ciência da Informação. Cabe ressaltar, ainda, que toda a produção de conhecimento da área da Informação está vinculada, essencialmente, a informações científicas e tecnológicas já armazenadas. Na Comunicação, entretanto, a produção de conhecimento decorre da informação produzida nas mídias e pelas diferentes relações permitidas por outros processos de mediação.

\section{Considerações finais}

O debate se mantém, então, entre duas áreas de conhecimento reunidas por decisões político-institucionais, mas que substituíram o distanciamento previsível por projetos comuns, legitimados historicamente, como demonstra a existência do PPGCOM/UFRGS. A convergência entre interesses acadêmicos dirigidos à formação de doutores e mestres com objetivos de produção de conhecimento tem fortalecido os vínculos institucionais entre Comunicação e Ciência da Informação.

O desafio reside na manutenção do debate sobre o paradoxo instituído por essas relações e dependências institucionais e estruturais que tanto aproximam os dois campos e a interdisciplinaridade na produção de conhecimento que não os reúne. São tensões que mantêm a vitalidade do PPGCOM/UFRGS. 


\section{Referências}

BARRETO, Aldo. 0 tempo e o espaço da Ciência da Informação. Transinformação, Campinas, v. 14, n. 1, p. 17-24, jan./jun. 2002. Disponível em: <http://periodicos.puccampinas.edu.br/seer/index.php/transinfo/article/view/1502>. Acesso em: 6 out. 2015.

BORKO, Harold. Information Science: what is it? American Documentation, New York, v. 19, n. 1, p. 3-5, Jan. 1968.

BRASIL. Lei no. 5.540, de 28 de novembro de 1968. Fixa normas de organização e funcionamento do ensino superior e sua articulação com a escola média, e dá outras providências. Diário Oficial [da] República Federativa do Brasil, Casa Civil, Brasília, DF, 23 nov. 1968.

CAPPARELLI, Sérgio; STUMPF, Ida Regina C. A constituição da Comunicação no Brasil como campo de conhecimento multidisciplinar. In: KRIEGER, M. da G.; ROCHA, M. A. (Orgs.). Rumos da pesquisa: múltiplas trajetórias. Porto Alegre: UFRGS, 1998. p.128-140.

CASTELLS, Manuel. A Sociedade em rede: a era da Informação, economia, sociedade e cultura. São Paulo: Paz e Terra, 2000.

CÁCERES, Jesús Galindo. De la sociedad de información a la comunidad de comunicación: la cibercultura en evolución a través de la vida social de las tecnologías de información y comunicación. Razón y Palabra, Atizapán de Zaragoza, v. 29, oct./nov. 2002. Disponível em: <http://www.razonypalabra.org.mx/anteriores/n29/jgalindo.html>. Acesso em: 7 dez. 2015.

BRASIL. Ministério da Educação. Coordenação de Aperfeiçoamento de Pessoal de Nível Superior. Plano Nacional de Pós-Graduação (PNPG) 2011-2020. Brasília, 2010.

FONSECA, Maria Odila. Ciência da Informação: denominação de curso e diretrizes curriculares. Transinformação, Campinas, v.14, n.1, p.101-104, jan./jun.2002.

LE COADIC, Yves-François. A Ciência da Informação. Brasília: Briquet de Lemos, 1996.

LOPES, Maria Immacolata V. de Lopes. (Org). Epistemologia da Comunicação. São Paulo: Loyola, 2003.

MARTINO, Luiz C. De qual comunicação estamos falando? In: HOHLFELDT, A.; MARTINO, Luiz C.; FRANÇA, Vera (Org.). Teorias da Comunicação: conceitos, escolas e tendências. Petrópolis, RJ: Vozes, 2001.

MCLUHAN, Marshall. Os meios de comunicação como extensões humanas. São Paulo: Cultrix, 1974.

MIÉGE, Bernard. L'Information-communication, object de connaissance. Bruxelas: De Boeck \& Larcier, 1995. 
STUMPF, Ida Regina e WEBER, Maria Helena. Comunicação e Informação: conflitos e convergências In: LOPES, Maria Immacolata V. de Lopes. (Org.). Epistemologia da Comunicação. São Paulo: Loyola, 2003. p. 121-134

TAVARES, Olga. Comunicação e Informação: caminhos de conexão. In: AQUINO, M. de A. (Org.). 0 campo da Ciência da Informação: gênese, conexões e especificidades. João Pessoa: UFPB, 2002. p.137-151

UNIVERSIDADE FEDERAL DO RIO GRANDE DO SUL. Programa de Pós Graduação em Comunicação e Informação. Projeto para programa de Doutorado. Porto Alegre, 2000.

WOLF, Mauro. Teorias da Comunicação. Lisboa: Presença, 1987.

\title{
Revisiting a debate: conflicts and convergence on communication and information
}

\begin{abstract}
This article is about the memory of the Post Graduate and Communications' Program of the Federal University of Rio Grande do Sul (UFRGS), as part of an ongoing debate on two fields of knowledge: Communications and Science of Information. Originally published in 2003, this article opens up the questioning on the paradox of the epistemological autonomy about the above referred fields, and the occurrence of its political and institutional dependency. In twenty years, the consolidation of PPGCOM/UFRGS responded to criticisms of successive evaluations and questionings in its concentration areas - Communication and Information. Both resistance and experience may actually contribute to the debate on its intrinsic interdisciplinary character of those sciences, according to the 2010-2020 National Plan for the Post Graduation Studies. Thus, in this direction this article's rewriting is based on historical and conceptual perspectives, which enable the identification of those three dimensions of Communication and information's Interdisciplinarity: dependency, mediation and intervention.
\end{abstract}

\section{Keywords}

Communication. Information. Interdisciplinarity. PPGCOM. UFRGS.

Recebido em 13/10/2015

Aceito em 15/12/2015 